Article

\title{
Kinetic Characterization of $\beta$-xylosidase (GbtXyl43A) from Wild-type Geobacillus thermoleovorans IT-08 and The Variant GbtXyl43A-D121N
}

Ika Fitriani Juli Palupi ${ }^{3}$, Kartika Dwi Asni Putri ${ }^{1,4}$, Ni Nyoman Purwani, ${ }^{2,4}$, Sri Sumarsih ${ }^{1}$, and Ni Nyoman Tri Puspaningsih ${ }^{1,4^{*}}$

${ }^{1}$ Department of Chemistry, Faculty of Science and Technology, Universitas Airlangga, Kampus C-UNAIR, Surabaya, 60115, Indonesia; kartika.dwi.asni-2019@fst.unair.ac.id (K.D.A.P.); sri-s@fst.unair.ac.id (S.S.).

${ }^{2}$ Department of Health, Faculty of Vocational Studies, Universitas Airlangga, Kampus B-UNAIR, Surabaya 60286, Indonesia; nyoman.purwani@ vokasi.unair.ac.id (N.P.).

${ }^{3}$ Department of Mineral Chemical Engineering, Polytechnic of Metal Industry, Morowali, 94974, Indonesia; palupi.ikafj@gmail.com (I.F.J.P.).

${ }^{4}$ Laboratory of Proteomics, University CoE-Research Centre for Bio-Molecule Engineering, Universitas Airlangga, Surabaya, Indonesia

* Correspondence: ni-nyoman-t-p@fst.unair.ac.id; Tel.: +62-0811-345-2009

\section{Abstract:}

GbtXyl43A, a $\beta$-xylosidase that is isolated from Geobacillus thermoleovorans IT-08 and grouped in GH43 family. The substitution of 121Asp residue with Asn in GbtXyl43A caused decrease the enzyme activity. The aim of this study, determine the kinetic characteristics of wild-type GbtXyl43A and D121N variant using $V_{\max }$, $K_{\mathrm{M}}, k_{\mathrm{cat}}$, and $k_{\mathrm{cat}} / K_{\mathrm{M}}$. These parameters indicated catalytic mechanism of GbtXyl43A and its derivative. All of them were produced in Escherichia coli BL21 star. The purification of wild-type GbtXyl43A using affinity chromatography, but D121N variant also required anion-exchange chromatography. The specific activity of wild-type GbtXyl43A and D121N variant were $0.471 \mathrm{U} \mathrm{mg}^{-1}$ in purity level 55,44 and $0.012 \mathrm{U} \mathrm{mg}^{-1}$ in purity level 2,407, respectively. Both enzymes had same molecular weight, $\sim 58 \mathrm{kDa}$. The kinetic parameters of wildtype GbtXyl43A were $K_{\mathrm{M}}: 2.845 \mathrm{mM}, k_{\text {cat }}: 0.033 \mathrm{~s}^{-1}, V_{\max }: 0.0033 \mathrm{mM} \mathrm{min}{ }^{-1}$ and $k_{\text {cat }} / K_{\mathrm{M}}: 0.0115 \mathrm{~s}^{-1} \mathrm{mM}^{-1}$. Furthermore, the $K_{\mathrm{M}}, k_{\mathrm{cat}}, V_{\mathrm{max}}$, and $k_{\mathrm{cat}} / K_{\mathrm{M}}$ values of $\mathrm{D} 121 \mathrm{~N}$ variant were $4.565 \mathrm{mM}, 1.01 \times 10^{-4} \mathrm{mM} \mathrm{min}^{-1}$, $0.140 \times 10^{-4} \mathrm{~s}^{-1}$, and $0.0307 \mathrm{~s}^{-1} \mathrm{mM}^{-1}$, respectively. The $K_{\mathrm{M}}$ value of the $\mathrm{D} 121 \mathrm{~N}$ variant was higher than its wild type and showed the affinity of D121N variant was lower than GbtXyl43A.

Keywords: Geobaccilus thermoleovorans IT-08; $\beta$-D-xylosidase; GbtXyl43A; kinetic characteristics

\section{Introduction}

Xylan is the main component of plant cell walls and one of the most abundant biopolymers on earth. It is composed of the major residues of $\beta$-D-xylopyranoside. Three major groups of enzymes involved in xylan degradation are xylanase, $\alpha$-glucuronidase, and $\beta$-xylosidase. $\beta$-Xylosidase serves to degrade xylan into free 
xylose [4]. $\beta$-D-xylosidase has an activity to hydrolyze xylan, thus $\beta$-D-xylosidase widely used by adding to commercial enzyme of hemicellulolytic to increase the xylan hydrolysis [6]. Applying the $\beta$-xylosidase enzyme with other glycohydrolases, such as endo-1,4- $\beta$-xylanases (EC 3.2.1.8), has increased, especially in biomedical research and industrial processes, such as those for pharmaceutical industries, bio-bleaching and biomechanics, pulping, wine production, baking, fruit, brewing, vegetable processing, and animal feed additives, as well as the production of bioethanol and other bioproducts [5].

Many pulping industries were done at high temperatures $\left(55-70^{\circ} \mathrm{C}\right)$ and in the alkaline conditions [6]. Chemical bleaching is generally used to facilitate several processes of pulping; thus, it is potentially toxic for the environment. Hence, alkaliphilic and thermophilic xylanase, which is operationally stable under such conditions, is required. Two types of thermophile $\beta$-D-xylosidases have been found from Geobacillus thermoleovorans IT-08. These enzymes are grouped into xylanolytic enzyme encoding genes: GbtXyl43A (xyl43A, GenBank No. DQ345777) and GbtXyl43B (xyl43B, GenBank No. DQ387047). Both enzymes exhibit differences in biochemical properties. GbtXyl43B has two modules: the catalytic module (CM), in the form of a five-bladed $\beta$-propeller; and the carbohydrate binding module (CBM), of which the kinetic parameters have been studied [12]. In addition, the CBM of GbtXyl43A is not functional; therefore, this enzyme is unable to hydrolyze oat-spelt xylan and has only a CM in the form of a five-bladed $\beta$-propeller $[6,11,12]$. However, the kinetic parameters of wild-type GbtXyl43A and its variants have not been studied. GbtXyl43A is classified into the GH43 enzyme group, which has a catalytic residue of Asp14 as a common base, Glu177 as a common acid, and Asp121 as a pKa modulator that directs the enzyme to the substrate [6,15].

The catalytic reaction of the GH43 enzyme group is based on an anomeric center inversion involving catalytic residues, aspartate, and glutamate, with a single substitution reaction. The effect of single amino acid substitution has been observed in several GH enzymes from Selenomonas ruminantium [8], Bacillus halodurans 
C-125 [15], and Geobacillus stearothermophilus [9], revealing changes of enzymatic kinetic parameters. Greater catalytic activities were observed for variant enzymes compare to the wild-type enzyme for the $\beta$-Dxylosidase of S. ruminantium, at 46\%, 71\%, and 48\%, respectively [8]. A study by Wagschal et al. (2012) on $\beta$-D-xylosidase XylBH43 from B. halodurans C-125 and the XylBH43-W147G variant demonstrated lowered substrate inhibition for both natural and artificial substrates, whereas the half-saturation constant $\left(K_{\mathrm{M}}\right)$ of the substrates increased [15]. Huang reported that for $\beta$-xylosidase from G. stearothermophilus, substitution of tyrosine 509 into glutamic acid leads to a new exoxylanase activity. The $K_{\mathrm{M}}$ and $k_{\text {cat }}$ values of the Y509E variant xylanase was determined using beechwood xylan as a substrate were $5.10 \mathrm{mg} / \mathrm{mL}$ and $22.53 \mathrm{~s}^{-1}$, respectively [9].

Kinetic parameters that used were derived from the Michaelis-Menten equation, including the maximum enzyme activity $(\operatorname{Vmax})$ and Michaelis constant $\left(K_{\mathrm{M}}\right)$, which has a role to measure the reflecting of the enzyme affinity [1].

The importance of Asp residue as a $\mathrm{pKa}$ modulator was described by Brux (2006). A similar study was conducted by Hartanti (2016). The substitution of the Asp121 residue from GbtXyl43A with glutamic acid (Glu), asparagine (Asn) and valine (Val) reduced the enzyme activity dramatically. The decrease in activity in the three variants showed a change of conformation due to the mutation. Thus, the substitution of Asp with Glu (D121E), Asn (D121N), and Val (D121V) caused some changes in the characteristics of GbtXyl43A, with respect to its $\mathrm{pH}$ and temperature optima [6]. Based on that analysis, it could be predicted that the GbtXyl43A variant had a lower affinity value against the substrate compared with its wild type. Enzymes with good catalytic properties (e.g., a high rate of substrate degradation) and acid-base-tolerance are needed in industrial process to reduce the production cost. Therefore, it is necessary to carry out advanced characterization of GbtXyl43A 
by specifying the kinetic parameters of the enzyme, which include $V_{\max }, K_{\mathrm{M}}, k_{\mathrm{cat}}$, and $k_{\mathrm{cat}} / K_{\mathrm{M}}$. The current study used the D121N variant because it has a higher $\mathrm{pH}$ and activity than those of the D121E and D121V variants.

\section{Materials and methods}

The materials that used in this study were Escherichia coli BL21 containing a wild-type GbtXyl43A gene and the D121N variant, were belong to Proteomic Laboratory, University CoE-Research Center for BioMolecule Engineering, Institute of Tropical Diseases, Universitas Airlangga, Surabaya, East Java, Indonesia.

\subsection{Expression and production of proteins}

The protein of GbtXyl43A was expressed in E. coli BL21 (DE3) which contained of pET-xyl plasmid and its purification had established [6]. First, pre-culture was prepared and incubated in $37^{\circ} \mathrm{C}$ for overnight. This pre-culture was used Luria-Bertani (LB) medium that supplemented with $100 \mu \mathrm{g} / \mathrm{mL}$ of ampicillin and grown by the recombinant plasmid E. coli BL21 (DE3)-pET-xyl. It was used $1 \%$ for inoculating in $1 \mathrm{~L}$ of fresh LB medium contained $100 \mu \mathrm{g} / \mathrm{mL}$ of ampicillin. The production was shaked until $\mathrm{OD}_{600 \mathrm{~nm}}$ value between 0.7 and $0.8( \pm 2.5 \mathrm{~h})$ and induced by $1 \mathrm{mM}$ isopropyl- $\beta$-D-thiogalactosidase for $3 \mathrm{~h}$ (wild-type GbtXyl43A) and $6 \mathrm{~h}$ (GbtXyl43A-D121N). The harvesting of cells was used centrifugation (3,500 rpm) for $30 \mathrm{~min}$ at $4{ }^{\circ} \mathrm{C}$. The pellet was resuspended by $10 \mathrm{mM}$ phosphate buffer ( $\mathrm{pH} 7.5)$. The phosphate buffer also contained of $10 \mathrm{mM}$ imidazole and $50 \mathrm{mM} \mathrm{NaCl}$. This solution of cells was sonicated. The supernatants of recombinant protein were taken after centrifugation $(10,000 \mathrm{rpm})$ for $15 \mathrm{~min}$ at $4{ }^{\circ} \mathrm{C}$.

\subsection{Purification of GbtXyl43A}

The protein of GbtXY143A was purified using affinity chromatography while the column containing nickelnitrilotriacetic acid (Ni-NTA) resin. First, the $1 \mathrm{~mL}$ column of Ni-NTA was washed by five column volumes of sterile aquabidest and buffer phosphate $\mathrm{pH} 8$ for equilibration. The buffer phosphate $\mathrm{pH} 8$ that used was 
containing of $50 \mathrm{mM}$ phosphate buffer, $250 \mathrm{mM} \mathrm{NaCl}$, and $10 \mathrm{mM}$ imidazole. Next, the supernatant as GbtXyl43A protein was loaded into the column. It was needed incubation at $0^{\circ} \mathrm{C}$ for $1 \mathrm{~h}$ for allowing the binding of protein. The flow through of this loading was collected for $1 \mathrm{~h}$. After that, the resin was eluted using elution buffer. The elution buffer was containing of $50 \mathrm{mM}$ phosphate buffer, $250 \mathrm{mM} \mathrm{NaCl}$, and $30 \mathrm{mM}$ imidazole. Wild-type GbtXyl43A was eluted using increasing imidazole concentration (60, 100, and $300 \mathrm{mM})$. Moreover, the GbtXyl43A-D121N variant was recovered by the imidazole concentration $(10,15,20$, and $30 \mathrm{mM})$.

Purification of the GbtXyl43A-D121N variant was continued using anion-exchange chromatography with the type of DEAE Toyopearl $650 \mathrm{M}$. The pre-equilibration was used Tris buffer that contain of $25 \mathrm{mM}$ Tris$\mathrm{HCl}$ buffer of $\mathrm{pH}$ 8.0. The fraction of Xyl was applied onto a $1 \mathrm{~mL}$ DEAE Toyopearl $650 \mathrm{M}$ anion-exchange column. This purification was eluted using linear gradient method of $\mathrm{NaCl}$ concentration. The concentration about $0-0.5 \mathrm{M} \mathrm{NaCl}$ in Tris buffer. The result of the elution was collected and analyzed using sodium dodecyl sulfate polyacrylamide gel electrophoresis (SDS-PAGE) by Laemmli method (1970). The concentration of purified protein was also determined using Bradford method (1976).

\subsection{Enzymatic activity}

The purified enzyme was analyzed about the activity using 2.0 M of $p$ NP-X ( $p$ NP- $\beta$-D-xylopyranoside) as a substrate. This analysis was incubated at $50^{\circ} \mathrm{C}$. The mixture solution for assay was contained of $450 \mu \mathrm{L}$ substrate in phosphate buffer and $50 \mu \mathrm{L}$ enzyme. The enzyme had pre-treatment by incubating at $50^{\circ} \mathrm{C}$ for 30 min. The analysis was continued by adding $50 \mu \mathrm{L}$ of $0,4 \mathrm{M} \mathrm{Na}_{2} \mathrm{CO}_{3}$ and measured at $400 \mathrm{~nm}$. The measurement was calculated in duplicate. the activity of recombinant GbtXyl43A was defined in one unit of activity (IU).

This analysis enzyme was required $1 \mu \mathrm{mol} p \mathrm{NP}$ per minute under reaction conditions.

\subsection{Enzyme kinetic assays}


The enzyme kinetic parameters that contained of $K_{\mathrm{M}}, V_{\max }, k_{\mathrm{cat}}$, and $k_{\mathrm{cat}} / K_{\mathrm{M}}$ were measured by observing the absorbance changes with a UV-Vis spectrophotometer at $405 \mathrm{~nm}$. The hydrolysis reaction was determined by incubating the $p \mathrm{NP}-\mathrm{X}$ substrate with a variety of concentrations $(0.5,2,4,6$, and $10 \mathrm{mM})$, as adapted from Wagschal (2009). The substrate was dissolved in phosphate buffer of $\mathrm{pH}$. The reaction was initiated by adding an enzyme solution to each substrate, which was incubated at $50^{\circ} \mathrm{C}$. Each reaction was observed at $0,6,14,22$, 30, 38, 46, and $54 \mathrm{~min}$. The initial velocity $\left(\mathrm{V}_{0}\right)$ of each substrate concentration was obtained from the linearity of each curve by plotting the incubation time on an axis and forming the product as an ordinate. Next, $K_{\mathrm{M}}, V_{\max }$, $k_{\text {cat }}$, and $k_{\text {cat }} / K_{\mathrm{M}}$ were determined using the Lineweaver-Burk plot.

\section{Results and discussion}

\subsection{Expression and purification of the wild-type GbtXyl43A and the D121N variant}

The $\beta$-D-xylosidase of wild-type GbtXyl43A and the D121N variant were expressed in E. coli BL21 and purified. To elucidate the xylanolytic activity on synthetic substrates, the GbtXyl43A properties were explored. Purified wild-type GbtXyl43A was recovered after an elution of buffer with $100 \mathrm{mM}$ imidazole concentration. A purified D121N variant was obtained using anion-exchange chromatography on four and five fractions. The fractions were analyzed using SDS-PAGE and stained with Coomassie blue. The purified enzyme showed a single band on the electropherogram, with a molecular weight of $\sim 58 \mathrm{kDa}$ (Figure 1). 


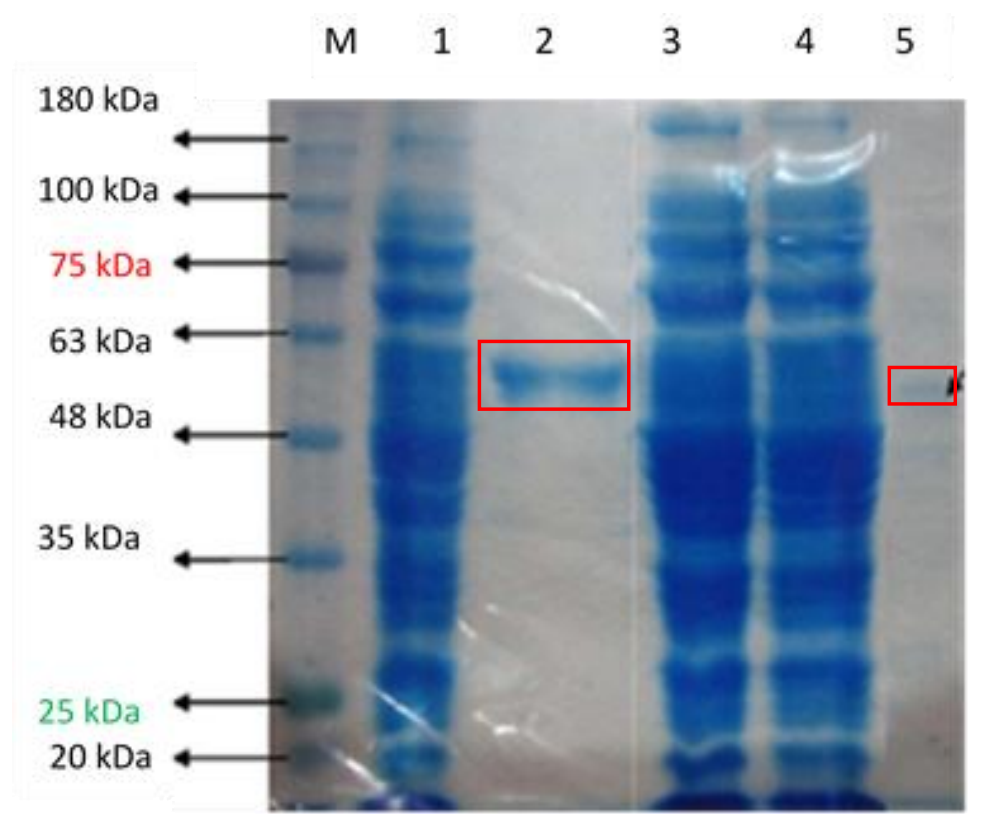

Figure 1. SDS-PAGE analysis of fractions obtained during the purification of GbtXyl43A. Lane M, protein marker; lane 1, crude extract wild type; lane 2, pure wild type; lane 3, crude extract D121N; lane 4, affinity extract D121N; lane 5, pure D121N.

The D121N variant was showed that the expression lower than wild-type GbtXyl43A. Mutations have been known to cause changes in protein folding and stability, protein function, and protein expression. In protein expression, mutations can speed or slow protein synthesis. The lower expression level of the D121N variant was showed that change in its optimum $\mathrm{pH}$ of enzyme activity and was significantly higher than the wild-type enzyme [6].

Table 1. Purification table of wild-type (WT) GbtXyl43A and D121N

\begin{tabular}{|c|c|c|c|c|}
\hline Sample & $\begin{array}{c}\text { Protein } \\
\left(\mathrm{mg} \mathrm{mL}^{-1}\right)\end{array}$ & $\begin{array}{c}\text { Activity } \\
\left(\mathrm{mL}^{-1}\right)\end{array}$ & $\begin{array}{c}\text { Specific Activity } \\
\left(\mathrm{mg}^{-1}\right)\end{array}$ & Fold \\
\hline WT: & 3.48054 & 0.02957 & 0.0085 & 55.44 \\
Crude extract & 0.39448 & 0.18584 & 0.4711 & 1 \\
Pure Enzyme & 5.29751 & 0.02731 & 0.00515 & 2.407 \\
D121N: & 0.06805 & 0.00084 & 0.01241 & \\
Crude Extract & & & & \\
Pure Enzyme & &
\end{tabular}




\subsection{The activity of GbtXyl43A and the D121N variant}

The enzyme of $\beta$-xylosidase that isolated from G. thermoleovorans IT-08 (Xyl) was grouped to the GH43 family. It has a three-dimensional structure that consist of a five-bladed $\beta$-propeller fold [13]. $\beta$-Xylosidase hydrolyzes the substrate with the use of a mechanism that leads to inversion the structure by the anomeric configuration. It was caused by the displacement of nucleophilic. There are three important residues that have role in catalytic site, they are Glu177, Asp14, and Asp121. The role of Glu177, Asp14, and Asp121 are as general acid, general base, and modulate the $\mathrm{p} K a$ of the acid and keeping all of them in the correct orientation toward to the substrate $[6,3,13]$.

In addition, to modulate the $\mathrm{p} K a$ of the catalytic acid, the residue had a role to guide the catalytic acid to the substrate. It was shown in the binding of 2-O of the sugar bond and subsite-1. It was influenced in the stabilization by the substrate's transition state. There was a mutation by changing the Asp into Asn (D121N) was decreased the active enzyme than the wild type did [6].

Wild-type GbtXyl43A showed the specific activity of $0.47110\left(\mathrm{U} \mathrm{mg}^{-1}\right)$, or 55.44 -fold over that of the activity of supernatant, when $p$ NP-X was used as a substrate. By contrast, the D121N variant exhibited a specific activity of $0.01241\left(\mathrm{U} \mathrm{mg}^{-1}\right)$, or 2.407-fold over that of the activity of its supernatant, when the same substrate was used (Table 1).

The activity of the $\beta$-D-xylosidase D121N variant was considerably lower than that of its wild type. The low activity value could have been due to the Asp121 substitution being Asn in the GbtXyl43A-D121N variant. This substitution caused a change in the nature of the enzyme. The GbtXyl43A-D121N variant had an optimal temperature and $\mathrm{pH}$ of $90^{\circ} \mathrm{C}$ and 9 , respectively, whereas the optimal temperature and $\mathrm{pH}$ of wild-type GbtXyl43A were $50^{\circ} \mathrm{C}$ and 6, respectively. Asp 121 mutation also caused changes in enzyme conformation. Asp121 plays a role as the pKa modulator and also keep it in the correct orientation to the substrate in the 
catalytic reaction. Asp substitution with Asn at the catalytic site reduced the enzyme's ability to hydrolyze the substrate.

Asn is a non-charged amino acid. Deep View analysis of the substitution that produce the variant was predicted that it changed into carboxamide function from the carboxylate function and it introduce a new hydrogen bond that showed by the O of Glu177 to HN of Asn121. The new hydrogen bonding had an interaction between these two residues because of the location was closer and also the differences of electronegativity $\mathrm{N}$ and $\mathrm{O}(\mathrm{N}<\mathrm{O})$. It's caused the ability of $\mathrm{N}^{\delta 2}$ in Asn121 to donate the proton to $\mathrm{O}^{\varepsilon 1}$ in Glu177. Thus, the Glu177 also needs a donation of proton. Besides, the optimal pH of the enzyme was decreased and changed to be alkaline. Otherwise, changing Asp into Asn increased the interaction of hydrophobic that happen on the catalytic area, and thus it also influenced the protein's stability [6].

\subsection{Enzyme kinetic assays}

The parameters of enzyme activity were obtained from the Michaelis-Menten equation as follows:

$V_{0}=V_{\max } \frac{[S]}{K_{M}+S}$

It then transforms into a new equation known as the Lineweaver-Burk plot [1].

$\frac{1}{V_{0}}=\frac{K_{M}+[S]}{V_{\max }[S]}$

where $\mathrm{V}_{0}$ is the velocity in the substrate reaction, Vmax is the maximum rate of enzyme activity at a reaction that given temperature, whereas the $K_{\mathrm{M}}$ is the half-saturation constant (Michaelis constant), and $[S]$ is the concentration of the substrate [7].

When the substrate concentration is greater than $K_{\mathrm{M}}$, the rate of catalysis is equal to $k_{\text {cat }}$ The kinetic constant $k_{\text {cat }}$ is the number of substrate molecules that converted into product per unit of time at a single catalytic site when the enzyme is fully saturated with the substrate. 
$V_{\max }=k_{\mathrm{cat}}[\mathrm{E}] \mathrm{T}$

The ratio of $k_{\text {cat }} / K_{\mathrm{M}}$ provides a penetrating probe into enzyme efficiency. To identify the Asp121 as the residue that had an important role to modulate the $\mathrm{p} K a$ of the general acid and also guide it in the correct orientation to the substrate, an extensive study was performed by mutating this residue into Asn, Val, and Glu [6]. In this work, we determined the kinetic parameters of the D121N variant by using $p$ NP-X as the substrate. We examined the D121N variant because it has the highest activity among the three variants.

The kinetic reaction of the $p$-nitrophenyl- $\beta$-D-xylopyranoside substrate by wild-type GbtXyl43A and the D121N variant was performed with a variety of substrate concentrations. An increased rate of product formation occurs with an increase in substrate concentration. In a relatively high substrate concentration, the reaction speed reaches a maximum. Therefore, a continuous monitoring method was applied to ascertain the initial-rate reactions for determining the kinetic parameters of the GbtXyl43A acting on the $p$ NP-X substrate.

The kinetic constants for the synthetic substrates were determined using Lineweaver-Burk plots (Figures 2 and 3). The wild-type enzyme exhibited kinetic constants for the hydrolysis of $p \mathrm{NP}-\mathrm{X}$, of $2.845 \mathrm{mM}$ and 0.0033 $\mathrm{mM} \min ^{-1}$ for $K_{\mathrm{M}}$ and $V_{\max }$, respectively. Furthermore, the D121N variant exhibited kinetic constants for the hydrolysis of $p$ NP-X, of $4.565 \mathrm{mM}$ and $0.101 \times 10^{-3} \mathrm{mM} \mathrm{min}^{-1}$ for $K_{\mathrm{M}}$ and $V_{\max }$, respectively (Table 2).

The $K_{\mathrm{M}}$ value of the GbtXyl43A-D121N variant was higher compared with its wild type, showing that the affinity of the D121N variant is lower than that of the wild type. The high value of $K_{\mathrm{M}}$ in the D121N variant is due to the amino acid substitution on the catalytic side. The substitution caused an alteration of enzyme conformation, thus decreasing the enzyme affinity for the substrate. 
Table 2. Kinetic parameter analysis for $p$ NP-X substrate hydrolysis by wild-type (WT) GbtXyl43A and the D121N variant

\begin{tabular}{|c|c|c|c|c|}
\hline Sample & $\begin{array}{c}\mathrm{K}_{\mathrm{M}} \\
(\mathrm{mM})\end{array}$ & $\begin{array}{c}\mathrm{V}_{\max } \\
\left(\mathrm{mM} \mathrm{min}^{-1}\right)\end{array}$ & $\begin{array}{c}\mathrm{kcat} \\
\left(\mathrm{s}^{-1}\right)\end{array}$ & $\begin{array}{c}\mathrm{Kcat} / \mathrm{KM} \\
\left(\mathrm{s}^{-1} \mathrm{mM}^{-1}\right)\end{array}$ \\
\hline WT & 2.845 & 0.0033 & 0.033 & 0.6922 \\
D121N & 4.565 & $0.101 \times 10^{-4}$ & $0.140 \times 10^{-4}$ & 0.037 \\
\hline
\end{tabular}

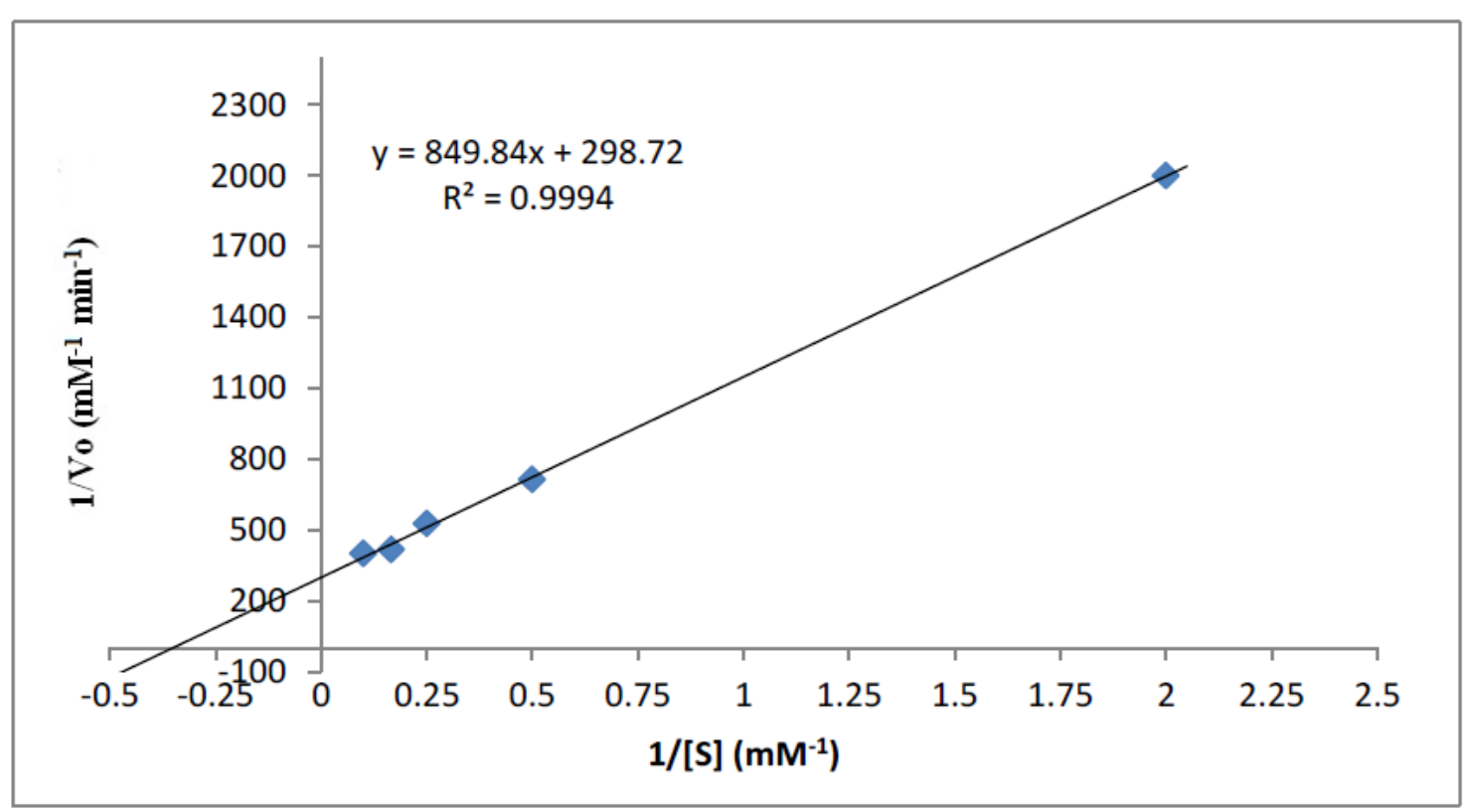

Figure 2. Lineweaver-Burk plot of kinetic parameter determination of the hydrolysis reaction of $p \mathrm{NP}-\mathrm{X}$ catalyzed by wild type GbtXyl43A

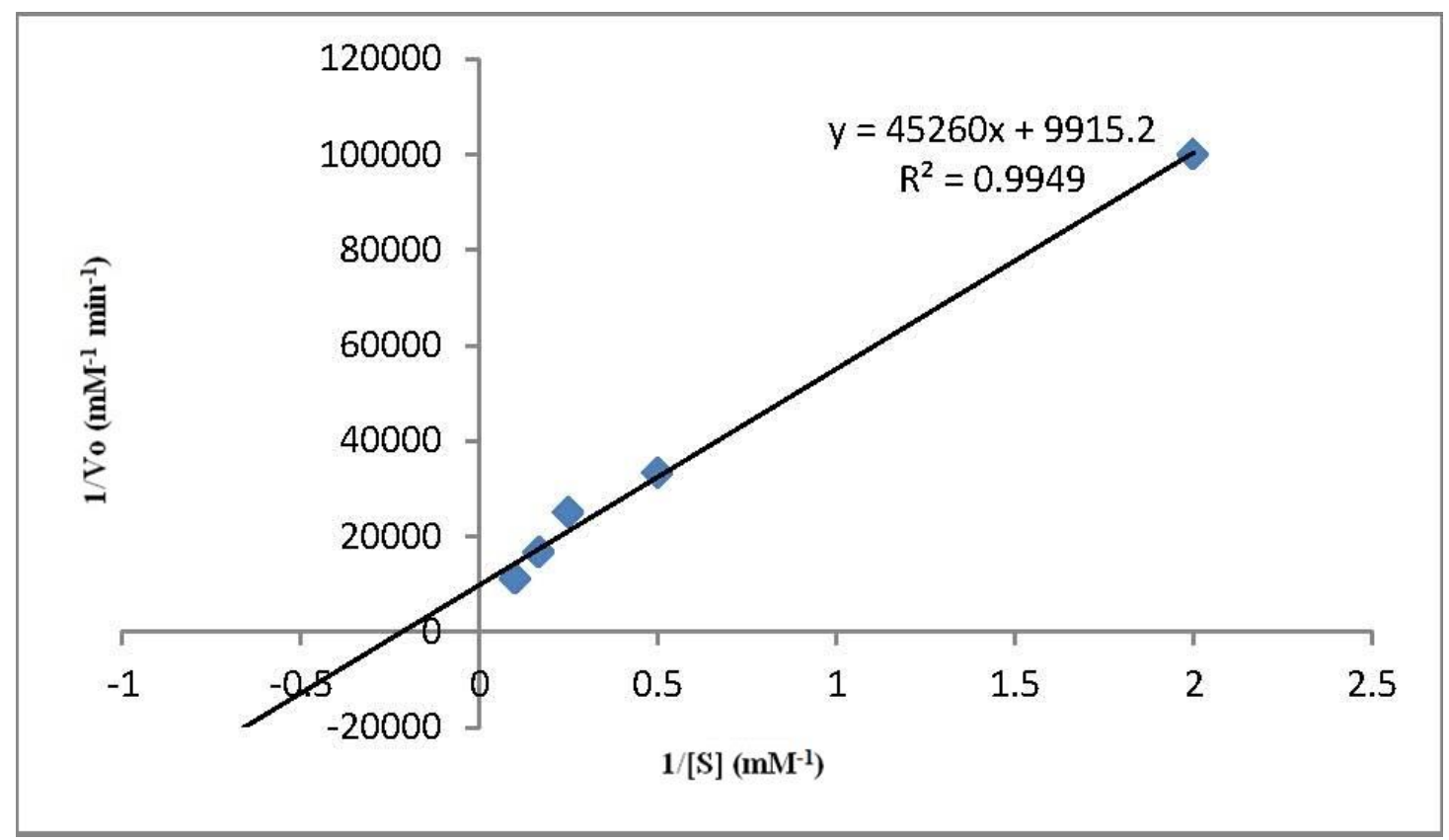

Figure 3. Lineweaver-Burk plot of kinetic parameter determination of the hydrolysis reaction of $\mathrm{pNP}-\mathrm{X}$ catalyzed by D121N 
Asn was thermolabile amino acid; however, the substitution was performed at the important residue at the catalytic site, a decrease in the bonding power of the substrate ensues. The $V_{\max }$ value expressed the velocity of the product formation of $p$-nitrophenol. The $V_{\max }$ value of the $\mathrm{D} 121 \mathrm{~N}$ variant was lower than that of its wild type, demonstrating that the speed of enzymatic reactions to produce the $p$-nitrophenol of the variant D121N is slower than that of the wild type.

The $k_{\text {cat }}$ values of wild-type GbtXyl43A and the variant D121N were $0.003 \mathrm{~s}^{-1}$ (or 1,969 $\mathrm{min}^{-1}$ ), and $0.140 \times 10^{-}$ ${ }^{4} \mathrm{~s}^{-1}$ (or $8.416 \times 10^{-4} \mathrm{~min}^{-1}$ ), respectively. Lastly, we determined the catalytic efficiency of the enzyme, expressed as $k_{\text {cat }} / K_{\mathrm{M}}$, which is a measure of substrate specificity. The $k_{\text {cat }} / K_{\mathrm{M}}$ value of the wild type and its variants were $0.692 \mathrm{~s}^{-1} \mathrm{mM}^{-1}$ and $0.0307 \mathrm{~s}^{-1} \mathrm{mM}$ (Table 2). Lower values of $k_{\text {cat }}$ and $k_{\text {cat }} / K_{\mathrm{M}}$ were also expected as a result of substitution at the catalytic site. Research by Jordan [7] on the $\beta$-SXA enzyme showed that a xylosidase yielded a $K_{\mathrm{M}}$ value of $0.0494 \mathrm{mM}$, whereas Singh [14] reported a $K_{\mathrm{M}}$ value of XylBH43 at $0.3 \mathrm{mM}$. The $K_{\mathrm{M}}$ value of the wild type and GbtXyl43A-D121N was higher than that of SXA or XylBH43, indicating that the wild-type and GbtXyl43A-D121N enzyme affinities were lower than those of SXA or XylBH43 against the $p$ NP-X substrate.

The wild-type GbtXyl43A $k_{\text {cat }}$ values $\left(0.03 \mathrm{~s}^{-1}\right)$ were lower than those of SXA $\left(27.3 \mathrm{~s}^{-1}\right)$ and XylBH43 $\left(17.9 \mathrm{~s}^{-}\right.$ ${ }^{1}$ ), indicating that the catalytic velocity process of the substrate-enzyme complex to the product on GbtXyl43A is slower than that of SXA or XylBH43. SXA, XylBH43, and wild-type GbtXyl43A had $k_{c a t} / K_{M}$ values of 55.2, 61.7, and $0.692 \mathrm{~s}^{-1} \mathrm{mM}^{-1}$, respectively. This revealed that the catalytic efficiency of wild-type GbtXyl43A is lower than that of SXA or XylBH43.

The substitution of aspartate (Asp121) with asparagine (Asn121) in $\beta$-D-xylosidase GbtXyl43A increased the optimal temperature and $\mathrm{pH}$. These changes were supported by their kinetic properties. 


\section{Conclusion}

We studied kinetic parameters, such as $K_{M}, V_{\max }, k_{c a t}$, and $k_{c a t} / K_{M}$, from wild-type GbtXyl43A and the D121N variant on $p$ NP-X substrates. The wild-type enzyme exhibits kinetic constants for the hydrolysis of $p$ NP-X, of $2.845 \mathrm{mM}$ and $0.0033 \mathrm{mM} \mathrm{min}^{-1}$ for $K_{\mathrm{M}}$ and $V_{\max }$, respectively. The $k_{\text {cat }}$ value of wild-type GbtXyl43A is 0.033 $\mathrm{s}^{-1}$ (or 1,969 $\left.\mathrm{min}^{-1}\right)$, and $\mathrm{k}_{\mathrm{cat}} / K_{\mathrm{M}}$ is $0.692 \mathrm{~s}^{-1} \mathrm{mM}^{-1}$. By contrast, the D121N variant exhibits kinetic constants for the hydrolysis of $p \mathrm{NP}-\mathrm{X}$, of $4.565 \mathrm{mM}$ and $0.101 \times 10^{-3} \mathrm{mM} \mathrm{min}^{-1}$ for $K_{\mathrm{M}}$ and $\mathrm{V}_{\max }$, respectively. The $k_{\mathrm{cat}}$ value of the GbtXyl43A variant is $0.140 \times 10^{-4} \mathrm{~s}^{-1}$, and the $k_{\text {cat }} / K_{\mathrm{M}}$ value is $0,0307 \mathrm{~s}^{-1} \mathrm{mM}^{-1}$. Further study should involve other substrates and analyze possible inhibitors during the catalytic reaction.

Author Contributions: Conceptualization, I.F.J.P., N.N.T.P, S.S. and N.P.; methodology, K.D.A.P., N.N.T.P, I.F.J.P. and S.S.; investigation, I.F.J.P., N.P.; writing-original draft preparation, I.F.J.P.; validation, I.F.J.P., N.N.T.P., S.S., N.P. and K.D.A.P.; writing - review and editing, N.N.T.P.; supervision, N.N.T.P. All authors have read and agreed to the published version of the manuscript.

Funding: This study was funded by the Directorate General of Higher Education, Ministry of Education and Culture, Indonesia.

Acknowledgments: Thank you to UCoE-Research Center for Bio-Molecule Engineering, Universitas Airlangga for the research facilities

\section{References}

1. Berg, J.M., Tymoczko, J.L., Stryer, L. Biochemistry. 9th ed. New York: W.H. Freeman and Company; 2019. 
2. Bradford, M.M., A rapid and sensitive method for the quantitation of microgram quantities of protein utilizing the principle of protein-dye binding. Anal Biochem. 1976;72;248-254 DOI: 10.1006/abio.1976.9999

3. Brüx, C., Ben-David, A., Shallom-Shefizi, D., Leon, M., The structure of an inverting GH43 $\beta$ xylosidase from Geobacillus stearothermophilus with its substrate reveals the role of the three catalytic residues. J Mol Biol. 2006;359;97-109. DOI: 10.1016/j.jmb.2006.03.005.

4. Eneyskaya, E.V., Ivanen, D.R., Bobrov, K.S., Biochemical and kinetic analysis of the GH3 family $\beta$ xylosidase from Aspergillus awamori X-100. Arch Biochem Biophys. 2006;457;225-234. DOI: 10.1016/j.abb.2006.10.024.

5. Gomes, E., Lembo, T., Da Silva, R. Production, characterization and properties of polysaccharide depolymerizing enzymes from a strain of Curvularia inaequalis. Folia Microbiol. 2001;46(4);303308. DOI: 10.1007/BF02815618

6. Hartanti, L., Rohman, A., Suwandi, A., Dijkstra, B.W., Nurahman, Z., Puspaningsih, N.N.T., Mutation analysis of the $\mathrm{pKa}$ modulator residue in $\beta$-D-xylosidase from Geobacillus thermoleovorans IT-08: activity adaptation to alkaline and high-temperature conditions. Procedia Chem. 2016;18;38-48. DOI: https://doi.org/10.1016/j.proche.2016.01.008

7. Jordan, D.B., Wagschal, K., Grigorescu, A.A., Braker, J.D., Highly active $\beta$-xylosidases of glycoside hydrolase family 43 operating on natural and artificial substrates. Appl Microbiol Biotechnol. 2013;97; 4415-4428. DOI: 10.1007/s00253-012-4475-4

8. Jordan, D.B., Wagschal, K., Fan, Z., Yuan, L., Engineering lower inhibitor affinities in $\beta$-D-xylosidase of Seleneomonas ruminantium by site-directed mutagenesis of Trp145. J Ind Microbiol Biotechnol. 
9. Huang, Z., Liu, X., Zhang, S., Liu, Z., GH52 xylosidase from Geobacillus stearothermophilus: characterization and introduction of xylanase activity by site-directed mutagenesis of Tyr509. J Ind Microbiol Biotechnol. 2013;41;65-74. DOI: 10.1007/s10295-013-1351-X

10. Laemmli, U.K., Cleavage of structural proteins during the assembly of the head of bacteriophage T4. Nature. 1970;227;680-685. DOI: 10.1038/227680a0

11. Purwani, N., Darmokoesoemo, H., Puspaningsih, N.N.T. Hydrolysis of corncob xylan using $\beta$ xylosidase GbtXyl43B from Geobacillus thermoleovorans IT-08 containing carbohydrate binding module (CBM). Procedia Chem. 2016;18;75-81. DOI: 10.1016/j.proche.2016.01.013

12. Ratnadewi, A.A.I., Fanani, M., Kurniasih, S.D., Sakka, M. $\beta$-Dxylosidase from Geobacillus thermoleovorans IT-08: biochemical characterization and bioinformatics of the enzyme. Appl Microbiol Biotechnol. 2013;170;1950-1964. DOI: 10.1007/s12010-013-0329-5

13. Rohman, A., Van Oosterwijk, N., Kralj, S., Dijkhuizen, L., Dijkstra, B.W., Puspaningsih, N.N.T., Purification, crystallization and preliminary X-ray analysis of a thermostable glycoside hydrolase family $43 \beta$-xylosidase from Geobacillus thermoleovorans IT-08. Acta Crystallogr F. 2007;63(1);932-

\section{DOI: 10.1107/S1744309107046015}

14. Singh, S.K., Heng, C., Braker, J.D., Chan, V.J., Lee, C.C., Jordan, D.B., Yuan, L., Wagschal, K., Directed evolution of GH43 $\beta$-xylosidase XylBH43 thermal stability and L186 saturation mutagenesis. J Ind Microbiol Biotechnol. 2014;41(3):489-98. DOI: 10.1007/s10295-013-1377-0

15. Wagschal, K., Heng, C, Lee, C.C,. Purification and characterization of a glycoside hydrolase family $43 \beta$-xylosidase from Geobacillus thermoleovorans IT-08. Appl Microbiol Biotechnol. 2009;155;304- 
16. Wagschal, K., Jordan, D.B., Braker J.D., Catalytic properties of $\beta$-Dxylosidase XylBH43 from Bacillus halodurans C-125 and mutant XylBH43-W147G. Process Biochem. 2012;47;366-372. DOI: 10.1016/j.procbio.2011.07.009 